\title{
Atualidades SOBRE OS VETORES E A TRANSMISSÃO DE ARBOVIROSES NO RIO DE JANEIRO
}

\author{
Ricardo Lourenço-de-Oliveira ${ }^{a}$
}

a Pesquisador Titular do Laboratório

de Mosquitos Transmissores de Hematozoários, Instituto Oswaldo Cruz, Fiocruz.

Av. Brasil, 4365 - Manguinhos, Rio de Janeiro.

E-mail: lourenco@ioc.fiocruz.br.

\section{RESUMO}

Arboviroses são agravos causados por vírus transmitidos por artrópodes. Desde 1986, o estado do Rio de Janeiro tem sido invadido por seis arbovírus epidêmicos transmitidos, coincidentemente, pelo mosquito urbano Aedes aegypti, culminando com a reemergência da febre amarela silvestre em 2017, cujos vetores primários, em contraste, são espécies de mosquitos silvestres do gênero Haemagogus. Neste artigo, comentamos essa sucessão de eventos epidemiológicos, dos pontos de vista histórico, ecológico e entomológico, e discutimos o risco da emergência de outros arbovírus no estado.

\section{Palavras-chave}

Reemergência, febre amarela, dengue, Zika, Chikungunya

\begin{abstract}
Arboviruses are diseases caused by viruses transmitted by the bite of infected arthropods. Since 1986, the state of Rio de Janeiro has been successively invaded by six epidemic arboviruses that shares the same urban mosquito vector Aedes aegypti, culminating in the reemergence of the sylvatic yellow fever in 2017, whose primary vectors, in contrast, are arboreal mosquito species of the genus Haemagogus. In this article, we comment on this succession of epidemiological events, from the historical, ecological, and entomological points of view, and discuss the risk of emergence of other arboviruses in the state.
\end{abstract}

\section{Keywords}

Re-emergency, yellow fever, dengue, Zika, Chikungunya 
As doenças infecciosas causam grande impacto na saúde mundial, em especial nos países subdesenvolvidos e em desenvolvimento localizados nas zonas tropicais e subtropicais. Digno de nota é o fato de que praticamente $70 \%$ das doenças infecciosas emergentes e reemergentes são transmitidas por artrópodes e de origem zoonótica, dentre as quais, as arboviroses tem enorme destaque $^{1,2}$.

Arboviroses são agravos causados por vírus, muito heterogêneos dos pontos de vista genético, molecular, estrutural e biológico, mas que possuem a particularidade comum de serem transmitidos entre hospedeiros vertebrados através de artrópodes hematófagos. Há mais de 500 arbovírus descritos e caracterizados, dos quais mais de 200 ocorrem no Brasil ou foram aqui originalmente descobertos; cerca de 110 são patogênicos para humanos em alguma parte do mundo e 40 destes são identificados como causadores de doenças de variado espectro sintomático em humanos no Brasil ${ }^{1,3-5}$. Curiosamente, mais da metade dos arbovírus já descritos no mundo têm mosquitos (Diptera: Culicidae) como vetores.

Os ciclos de transmissão dos arbovírus são complexos, dependem de numerosas e intrincadas interaçôes com hospedeiros vertebrados e os invertebrados vetores, governadas por fatores que vão desde a genética dos hospedeiros e vírus, até as condições am- bientais e climáticas ${ }^{4,6,7}$. Conhecem-se arbovírus que podem infectar e produzir viremia em vertebrados pertencentes a Classes muito distintas como aves, répteis e mamíferos e são capazes de infectar e ser transmitidos por artrópodes de diferentes famílias. Um exemplo ilustrativo é o caso do vírus do Oeste do Nilo (WNV), que infecta de crocodilos a humanos, passando por várias Ordens de aves e mamíferos. Mas, a competência e a capacidade para transmissão do WNV variam consideravelmente entre artrópodes e mamíferos. Humanos e equinos, por exemplo, são fins de linha em seu ciclo, pois embora possam sofrer lesóes neurológicas graves e morrer devidos à infecção por este arbovírus, produzem viremia com títulos abaixo do necessário para infectar os vetores ${ }^{8-10}$. Acredita-se, assim, que a maioria dos arbovírus seja mais específica quanto aos hospedeiros vertebrados e invertebrados onde se replicam alternada e ciclicamente para se manter na natureza $^{4,11}$.

Nas últimas quatro décadas, o Brasil sofreu severas epidemias causadas por arbovírus exóticos ao nosso território. O estado do Rio de Janeiro teve papel importante, seja como local provável de introdução e/ou exercendo função decisiva no processo de dispersão territorial devido a sua vocação turística, posse de considerável rede rodoviária e aeroviária de comunicação com o exterior e restante do país, além de condiçóes urbanas e infraestrutura sanitária caóticas em considerável 
parte da chamada grande área metropolitana. Ainda que haja indícios sorológicos e epidemiológicos da circulação pregressa de alguns arbovírus naturais do continente americano no Rio de Janeiro (Encefalite Saint Louis, Ilhéus e Bussuquara) $)^{12-14}$, os graves episódios epidêmicos a que nos referimos foram devidos aos flavivírus Dengue (DENV1, DENV2, DENV3 e DENV4), Zika (ZIKV) e Febre Amarela (YFV) [família Flaviviridae, gênero Flavivirus] e ao alfavírus Chikungunya (CHIKV) [família Togaviridae, gênero Alphavirus). Esses vírus, originários da África e Ásia, encontraram em nosso território, em diferentes momentos históricos, alta taxa de infestação por um vetor susceptível, coincidentemente também importado da África, o mosquito Aedes (Stegomyia) aegypti ${ }^{7,15}$.

O subgênero Stegomyia, a que pertence essa importante e notória espécie de mosquito, é nativo do Velho Mundo, com ocorrência original concentrada nos continentes africano e asiático, onde os supracitados arbovírus, esses mosquitos e seus reservatórios vertebrados coevoluíram. Duas espécies de Stegomyia se dispersaram para diversas partes do mundo, em diferentes momentos, às custas de transporte passivo promovidos por atividades humanas, como o comércio intercontinental: Ae. aegypti e Ae. albopictus. Essas espécies compartilham as características biológica e comportamental de depositarem seus ovos resistentes à dessecação nas paredes internas de recipientes. Aderidos, os ovos podem ser transportados nos recipientes para longas distâncias e eclodirem quando e onde forem submersos pelas águas das chuvas ou de uso doméstico ${ }^{15}$, o que traz duas vantagens biológicas importantes: auxiliam na perpetuação e na disseminação das espécies, mas conferem grande dificuldade para o seu controle.

O Ae. albopictus, mosquito conhecido como tigre asiático, iniciou a sua dispersão para fora de seu território original bem recentemente, em especial a partir da década de 1980. Do Sudeste da Ásia, já invadiu e colonizou países de todas as Américas, Europa, especialmente mediterrânea, África e Austrália ${ }^{16,17}$. Ae. albopictus ainda não foi incriminado na transmissão de arbovírus no Brasil, embora tenha sido responsável pela transmissão epidêmica de DENV e CHIKV, na Europa e Oceano Índico, e encontrado infectado com ZIKV na África ${ }^{17-19}$.

Em contraste, Ae. aegypti vem colonizando as Américas, inclusive o Caribe, há mais de 400 anos, às custas do tráfico de escravos e mercadorias, notadamente a partir da costa oeste africana. Mais tardiamente, nos séculos XIX e XX, dispersou-se e colonizou a Ásia, Oceania e o Pacífico, além de realizar introduçóes ou mesmo estabelecimento sustentado em áreas restritas da Europa ${ }^{11,15,20-22}$. Ainda que no seu território de origem, a África, o Ae. aegypti mantenha uma forma essencialmente silvestre, aquela que se dis- 
persou pelo mundo é doméstica e antropofílica, vivendo exclusivamente associada aos humanos. Essa forma ou raça doméstica tem como focos larvares recipientes contendo água estagnada de aspecto geral limpo produzidos pelo próprio homem e disponíveis dentro ou nos arredores das residências e edifícios para outros usos ${ }^{15}$. Essa particularidade ecológica e comportamental fez desse mosquito um excelente vetor de arbovírus entre humanos, em especial do YFV, seja no solo africano, seja nas Américas. Com efeito, no Brasil, a propagação intensa do Ae. aegypti nas áreas urbanas, especialmente portuárias, no tempo colonial, permitiu a instalação e sustentou a transmissão epidêmica do YFV em episódios importantes da história da medicina brasileira ${ }^{20,23}$. Tal como o Ae. aegypti, a febre amarela também é originária da África e foi, por séculos, conhecida como uma antroponose urbana. No Rio de Janeiro, a primeira epidemia de febre amarela registrada data de 1849, ainda que haja suspeitas de transmissão anterior ${ }^{23}$. A última epidemia de febre amarela que atingiu o estado do Rio de Janeiro foi registrada no final da década de 1930, quando se iniciava a vacinação com o vírus atenuado $17 \mathrm{D}$ no país. As campanhas de vacinação contra o YFV e de erradicação continental do vetor Ae. aegypti, resultaram na eliminação da transmissão urbana da febre amarela no Brasil ${ }^{23,24}$. Por décadas, o Rio de Janeiro não registrou casos de febre amarela e, subsequentemente, deixou de figurar no mapa nacional de recomendação de vacinação contra o YFV ${ }^{23,25}$. Seguiu-se uma trégua de quase 80 anos sem febre amarela no estado, interrompida pela maior epidemia registrada no país, em 2017-2019²4, como comentaremos à frente.

Contudo, entre os anos 1940 e a supracitada reemergência da febre amarela, o Rio de Janeiro foi invadido por outros seis arbovírus exóticos e epidêmicos, todos transmitidos por Ae aegypti. Essas epidemias por arbovírus têm desestabilizado o sistema de saúde e levado à morte ou deixado sequelas graves nos fluminenses desde os anos 1980. Esse silêncio epidemiológico das décadas de 1940 a 1980 foi resultado do êxito da campanha de erradicação do Ae. aegypti, onde o Brasil foi diplomado como livre desse mosquito em 195515,23,26. A redução da densidade desse vetor nos primeiros terços da campanha e o seu desaparecimento no meado do século XX tornou o país não receptivo à transmissão de arbovírus dependentes do Ae. aegypti. Porém, a re-infestação do Brasil pelo Ae. aegypti a partir do final da década de 1960 e início dos anos 1970, combinada com o relaxamento da vigilância e controle deste mosquito, em parte justificados pela eficiência e eficácia da vacinação anti-amarílica, resultou, em pouco mais de uma década, na infeliz presença ubíqua e abundante desse vetor ${ }^{15,26}$. Alguns fatores são frequentemente apontados como causas dessa falha na contenção dessa recolonização 
e altas taxas de infestação pelo Ae. aegypti na contemporaneidade: a crescente resistência de suas populaçóes aos inseticidas utilizados contra as formas imaturas e adultas, o indiscriminado uso e descarte indevido de recipientes, a desorganização urbana e as baixas condiçôes de infraestrutura e saneamento básico, que, dentre outras coisas, levam ao armazenamento impróprio de água ${ }^{26}$. O Rio de Janeiro, por sofrer crescentemente desses últimos problemas, tornou-se uma das unidades federativas mais receptivas e vulneráveis à transmissão urbana e periurbana, por Ae. aegypti, de arbovírus ainda sem vacina eficaz disponível, a começar pelos DENVs. Os DENVs, que se tornaram pandêmicos, tiveram origem na Ásia, em especial no Sudeste asiático. Após a segunda guerra mundial já produziam epidemias importantes e, a partir dos anos 1960, se instalaram nos pa- íses do Caribe e das Américas continentais que não erradicaram o Ae. aegypti27,28.

Uma sequência de introduçóes de arbovírus, com subsequentes epidemias explosivas, que ocorrem geralmente entre um e dois anos após a confirmação laboratorial dos primeiros casos, têm sido registradas no estado do Rio de Janeiro desde 1986 (Figura 1). Os DENV1, DENV2, DENV3 e DENV4 foram diagnosticados pela primeira vez no Rio de Janeiro em 1986, 1990, 2000 e 2011, respectivamente. Coincidentemente, os primeiros diagnósticos de cada um deles foram feitos na regiáo Metropolitana do estado: DENV1 e DENV3, em Nova Iguaçu, e DENV2 e DENV4, em Niterói. O primeiro deles (DENV1), ainda que detectado cinco anos antes em Roraima e ali restrito ${ }^{29}$, teve uma reintroduçáo e subsequente disseminação no Brasil a partir da chegada e produçáo

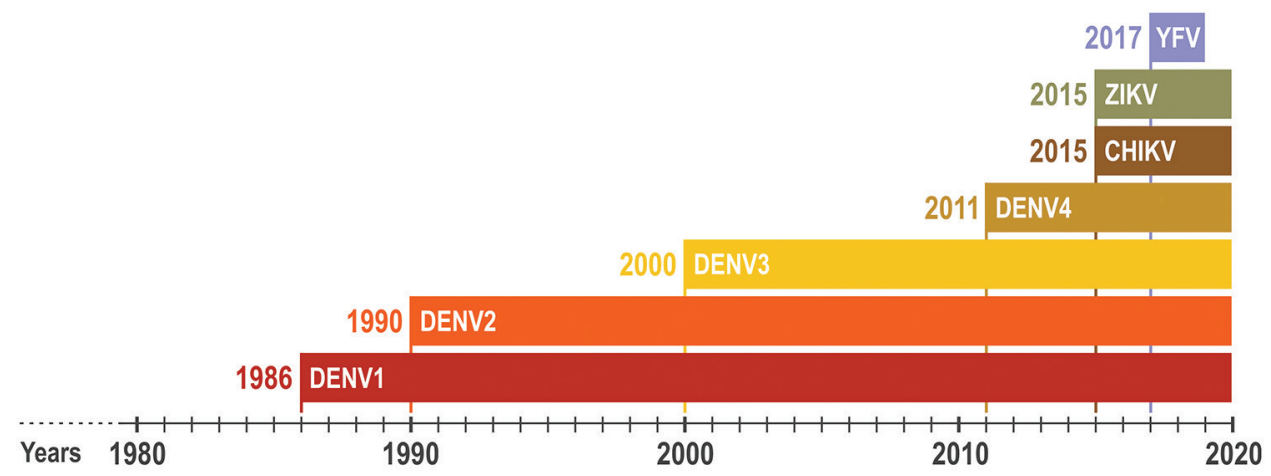

Figura 1: Sucessão temporal da detecção de arbovírus epidêmicos no estado do Rio de Janeiro: Dengue (DENV), Chikungunya (CHIKV) e Zika (ZIKV) de circulação urbana e transmitidos entre humanos por Aedes aegypti, e Febre Amarela (YFV) de natureza zoonótica e transmitido primariamente por mosquitos silvestres do gênero Haemagogus. 
de uma epidemia, com 92 mil casos, no Rio de Janeiro, em 1986-198730. A introdução do DENV2 enquanto o DENV1 ainda circulava ativamente resultou numa epidemia, em 1990-1991, em que os primeiros casos de dengue hemorrágica no estado foram reportados $^{31,32}$. Dez anos depois, em dezembro de 2000, também é no estado do Rio de Janeiro que se detecta a circulação de um novo sorotipo no Brasil, o DENV-3, sendo este o responsável pela maior e mais grave epidemia de dengue registrada no país até o ano de $2002^{32,33}$. É na próxima década que, logo depois de causar um surto em Roraima em 2010, o DENV-4 é detectado a primeira vez no Rio de Janeiro, no transcurso de uma epidemia explosiva por DENV-1, sendo o sorotipo predominante nas epidemias de 2012 e 2013, tanto nesse estado quanto no Brasil como um todo ${ }^{34,35}$. A essa altura, a vigilância virológica revelou que o estado teria se tornado endêmico para os quatro sorotipos de DENV, com a detecção da circulação de todos eles, em prevalências distintas, a partir de amostras de pacientes ou de mosquitos $^{36-38}$.

Apenas dois anos depois, o Rio de Janeiro detecta a circulação de outros dois arbovírus exóticos transmitidos pelo Ae. aegypti: CHIKV e ZIKV. Os primeiros casos autóctones de Chikungunya foram diagnosticados no Rio de Janeiro em 2015, tanto na região metropolitana (Niterói e capital) quanto em Angra dos Reis. Tratava-se de infecçôes pelo genótipo Leste-Centro-Sul Africano (ECSA) do CHIKV, o único circulante no estado até o presente momento ${ }^{39}$, ainda que o genótipo Asiático tenha sido aquele causador da primeira epidemia registrada no continente americano, em 2013-2014, quando também foi detectado no Amapá ${ }^{40}$. Análises do genoma de amostras do genótipo ECSA indicaram que a transmissão autóctone do CHIKV poderia estar ocorrendo silenciosamente no estado do Rio de Janeiro desde início de $2014^{41}$, ano em que a vigilância só detectara casos importados ${ }^{42}$. O primeiro pico epidêmico se deu em 2016, com 14.632 casos confirmados por CHIKV, 99,3\% deles ocorridos na capital do estado ${ }^{42,43}$. A partir de então o CHIKV se tornou endêmico no estado, co-circulando com os DENVs às custas da transmissão vetorial exclusiva pelo $A e$. aegypti, ainda que populaçóes locais do $A e$. albopictus se mostrassem experimentalmente competentes tanto para CHIKV quanto para alguns sorotipos de DENVs ${ }^{7,44-46}$.

Foi também em 2015 quando se diagnosticaram os primeiros casos de Zika no Rio de Janeiro ${ }^{47,48}$. Ainda que o ZIKV seja originário da África, o genótipo que invadiu o Brasil e chegou ao Rio de Janeiro, depois de ter sido detectado, no mesmo ano, no Nordeste, foi o asiático ${ }^{47}$. Em 2015, a vigilância sentinela consegui detectar apenas cerca de 500 casos no estado, com a confirmação laboratorial de $15 \%{ }^{49}$. Mas, ainda em 2015, com a associação da infecção pelo ZIKV com 
manifestações neurológicas graves, inclusive o nascimento de crianças com microcefalia, Zika foi declarada emergência mundial, havendo um aprimoramento na vigilância universal $^{48,49}$. A histórica epidemia por ZIKV no estado do Rio de Janeiro ocorreu em 2016, com mais de 71 mil casos suspeitos e de 46 mil confirmados laboratorialmente ${ }^{50}$, ano em que também se detectou a presença de partículas virais infectantes em saliva e urina de residentes no estado ${ }^{51}$, ajudando a confirmar que o ZIKV pode ser transmitido tanto diretamente entre humanos quanto por via vetorial $^{52}$. Aliás, dentre as formas alternativa de transmissão do ZIKV, confirmou-se ocorrer a venérea e a vertical, tanto entre humanos quanto entre mosquitos Ae. aegypti ${ }^{52,53}$, o que favorece a perpetuação deste arbovírus na natureza.

O ano de 2016 finaliza com o estado do Rio de Janeiro contabilizando um total de 173.908 casos prováveis de arboviroses, correspondendo a uma incidência total de 1.051 casos/ 100 mil hab devido aos DENVs (86.594 casos; 16 óbitos), CHIKV (15.698 casos, 14 óbitos) e ZIKV (71.616 casos; 5 óbitos) $)^{54}$.

É coincidentemente nas últimas semanas de 2016 que se detecta um aumento no número de notificações de febre amarela silvestre em Minas Gerais, com destaque para a porção mais oriental mineira, de onde o YFV invadiria, pela primeira vez, depois de quase 80 anos, a mata Atlântica do Espírito
Santo, em janeiro de 2017. Em dois meses, em março de 2017, epizootias em primatas não-humanos (PNHs) e casos humanos já eram detectados no estado do Rio de Janeiro. Era o início de um surto sem precedente no sudeste brasileiro e mesmo na história desse agravo no Brasil ${ }^{55}$. O país registrou 2.259 casos humanos confirmados e 773 mortes injustificáveis para o país que produz cerca de $80 \%$ das doses de vacina anti-amarílica usada em todo o mundo e onde a vacinação é gratuita ${ }^{24}$. Cerca de $98 \%$ desses casos foram adquiridos no bioma da Mata Atlântica e transição entre este e o do Cerrado do Sudeste ${ }^{56}$.

A zona mais oriental da Região Sudeste sob influência da mata Atlântica, aí incluindo-se toda a área dos estados do Rio de Janeiro e Espírito Santo, assim como parte de São Paulo, estava há décadas fora da área de recomendação de vacina antiamarílica ${ }^{25,55}$. Consequentemente, em janeiro de 2017 a cobertura vacinal no Rio de Janeiro era baixíssima. A rica fauna de $\mathrm{PNH}$ s dessa zona, incluindo espécies endêmicas e ameaçadas de extinção - como o mico-leão dourado no Rio de Janeiro, altamente sensível ao $\mathrm{YFV}^{57}$ - não era imune ao $\mathrm{YFV}^{58}$. Portanto, a iminente disseminação do YFV representava uma enorme ameaça à saúde humana e à biodiversidade ${ }^{55,58}$.

Essa onda epidêmica que chegou ao Rio de Janeiro se iniciou na Amazônia, em 2014, e sua trajetória em direção ao sul 
seguiu a bacia dos rios Tocantins-Araguaia, onde causou epizootias e deu origem a casos humanos essencialmente isolados em Goiás, a despeito da considerável cobertura vacinal local. A partir de Goiás, o YFV ganhou duas bacias hidrográficas, originando-se duas sublinhagens virais distintas genética e molecularmente. A que migrou pela bacia do rio Paraná, produziu epizootias e casos humanos desde o sudoeste de Minas Gerais até a grande área metropolitada da capital paulista, ao passo que a outra sub-linhagem migrou da bacia do rio São Francisco à grande bacia denominada Atlântico Sudeste, que reúne várias sub-bacias costeiras, atingindo o leste de Minas Gerais e, na sequência, os estados do Espírito Santo e Rio de Janeiro ${ }^{59}$. Esta última sub-linhagem é a que nos interessa quanto ao presente texto. Primeiramente, porque ela apresentou uma assinatura molecular singular, jamais vista, composta de nove polimorfismos, localizados em áreas importantes da replicação viral. Em segundo lugar, ela gerou duas sub-cadeias de transmissão que atravessaram o território do estado do Rio de Janeiro, de nordeste a sudoeste. Curiosamente, estas sub-cadeias se deslocaram paralelamente e de maneira quase independente, cada qual por um dos lados da Serra do Mar: uma pelo norte, ou porção continental, e a outa pelo sul, ou faixa litorânea ${ }^{59,60}$. Verificou-se que o Estado era altamente receptivo do ponto de vista entomológico, com os vetores silvestres primários bem distribuídos em seu territó- rio $^{61}$. Em 2017, de março a junho, o YFV atingiu municípios das regióes Noroeste e Norte Fluminenses, Serrana, Baixada Litorânea e Metropolitana e, em 2018, acometeu especialmente o Centro-Sul, Médio Paraíba e Costa Verde/Baía da Ilha Grande ${ }^{62,63}$. As regiōes Serrana e Metropolitana foram atingidas nos dois anos, o que gerou grande preocupação devido ao fato que, na última, a elevada densidade demográfica com baixa cobertura vacinal em alguns setores e os altos índices de infestação pelo vetor urbano $A e$. aegypti, aumentavam o risco de reurbanização da febre amarela ${ }^{24,55,61}$, o que, felizmente, não aconteceu. Não houve evidências de transmissão autóctone na capital do estado. Porém municípios da grande região metropolitana, como Nova Iguaçu e Maricá, registraram epizootias e casos humanos, inclusive óbitos. As ações de bloqueio contra o Ae. aegypti e a intensificação de vacinaçóes efetuadas oportunamente desde o início de 2017 devem ter sido fundamentais para evitar a transmissão urbana, embora quase a metade do território ainda tivesse cobertura vacinal de $\leq 79 \%$ em meados de $2018^{63}$.

O YFV ainda se mostrou ativo em início de 2019 no estado, com epizootia na região da Baixada litorânea, quando a análise do genoma viral mostrou que o YFV manteve circulação por três estaçóes de transmissão seguidas numa mesma zona de mata Atlântica, fato inédito ${ }^{62}$. Com efeito, a literatura tem mostrado que, fora da Amazônia, 
região onde há circulação endêmica e quase permanente, o YFV causa epizootias que se desdobram em surtos passageiros, desaparecendo até que uma nova onda, originária na Amazônia, ali chegue. Em vista da fragmentação das florestas fluminenses e de grande parte do Sudeste, por onde o YFV passa, o vírus acaba por matar uma grande parte dos PNHs e deixar parte deles imunizada, restando poucos susceptíveis nos fragmentos, o que reduz a chance da transmissão. Alguns autores fazem uma analogia da natureza da disseminação espaço-temporal do YFV com um incêndio florestal, que se desloca rapidamente, deixando para trás um terreno destruído e onde os ciclos naturais demorarão a se reconstituir ${ }^{64}$, ou seja, fica de certa forma "imune" a novas queimadas durante algum tempo. Em 2017-2019, esse deslocamento do YFV teve momentos de maior velocidade, em especial nos meses de dezembro a abril, coincidindo com a estação quente e chuvosa no Sudeste, período em que se concentraram os maiores registros de casos humanos e epizootias de PNHs. Durante a passagem dessa onda epizoótica no Rio de Janeiro, assim como no Espírito Santo e São Paulo, verificou-se que a velocidade de deslocamento estaria em torno de $3,0 \mathrm{~km} / \mathrm{dia}^{59}$.

Tanto a incidência de infecçóes humanas e de PNHs quanto a velocidade de deslocamento do YFV são influenciadas pela biologia e comportamento dos mosquitos silvestres vetores primários, que, no Rio de
Janeiro, constatou-se serem Haemagogus leucocelaenus e Haemagogus janthinomys/capricornii ${ }^{58,61}$. Essas espécies depositam seus ovos, resistente à dessecação, em ocos de árvores, cujo preenchimento pelas precipitaçóes maiores do verão estimula a eclosão das larvas e aumento rápido da densidade populacional desses mosquitos na floresta, intensificando-se, assim, a transmissão nesse período do ano ${ }^{15,56}$. Com efeito, verificou-se que o número de ovos de $\mathrm{Hg}$. leucocelaenus aumenta expressivamente na mata Atlântica do Rio de Janeiro quando a temperatura média e a precipitação acumulada ultrapassam $27^{\circ} \mathrm{C}$ e $100 \mathrm{~mm}$, respectivamente ${ }^{65}$. A capacidade de voar longas distâncias em poucos dias já demonstrada por esses mosquitos $(5,7 \mathrm{~km}$ para $H g$ leucocelaenus e $11,5 \mathrm{~km}$ para $H g$. janthinomys/capricornii), inclusive atravessando áreas desmatadas no percurso, favorece sobremaneira a dispersão dessa arbovirose entre fragmentos de matas ${ }^{66}$. Aliás, a informação de que o surto de febre amarela fluminense era de caráter silvestre criou uma noção errada na população de que só se adquiriria a infecção ao se entrar na mata. Porém, a picada infectante de Heamagogus pode ocorrer fora da mata, como nos quintais e varandas de casas de zonas urbanas e periurbanas próximas de matas, o que fez várias vítimas desavisadas ${ }^{55}$. Dentro da floresta, o hábito hematofágico desses dois mosquitos, seja em relação ao horário e à altura em que voam preferencialmente para picar $^{67,68}$, coin- 
cidem com os mais favoráveis para atacar os PNHs, quando boa parte destes últimos está repousando nas horas mais quentes em torno do meio do dia (Figura 2), aumentando as chances de se infectarem nesses reservatórios do YFV. Dentro e fora da mata, porém, humanos e PNHs podem ser infectados pela picada destes mosquitos em qualquer das horas claras do dia.

Durante o surto (2017-2018), o Rio de Janeiro reportou 1.604 casos suspeitos de febre amarela, confirmando-se a etiologia em 307 deles (19,1\%), com 105 óbitos (uma taxa de letalidade de $34,2 \%)^{55}$. Após o surto, não se registram casos humanos pelo YFV no Rio de Janeiro em 2019 e $2020^{69}$.

Diferentemente das arboviroses como dengue, Chikungunya e Zika, de transmissão entre humanos pelo Ae. aegypti, cujo combate mecânico e químico dos focos larvais desse vetor comum entre elas pode ser eficiente, a febre amarela silvestre não pode ser controlada ou erradicada com combate semelhante contra os seus vetores, pois os focos larvais dos Haemagogus são ocos de árvore, muitas vezes localizados na copa da floresta ou em
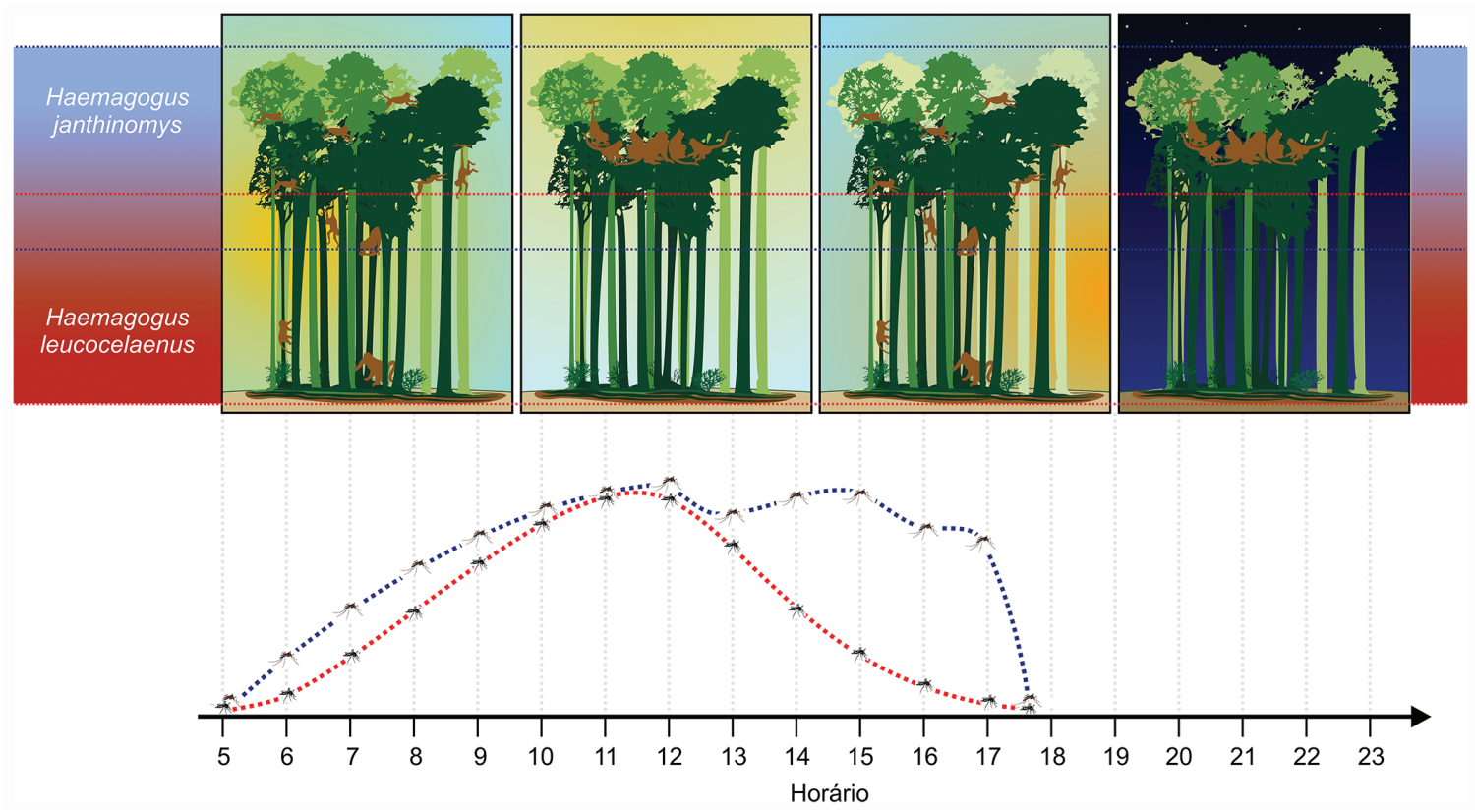

Figura 2: Hábitos hematofágicos na floresta das espécies de mosquitos vetores primários durante o surto decorrente da reemergência da febre amarela silvestre no estado do Rio de Janeiro: Haemagogus janthinomys (azul) e Haemagogus leucocelaenus (vermelho). Distribuição vertical (superior) e horária (inferior) dominante da picada dos mosquitos em relação aos hábitos dos primatas não humanos. 
locais crípticos. Portanto, a vacinação e a informação em saúde, em especial a adoção de métodos de proteção pessoal à picada, são as armas que temos para controlar o YFV. É, portanto, imperativo que a vigilância, especialmente de epizootias, seja ininterrupta e estimulada e que os índices de cobertura vacinal sejam mantidos elevados no estado para se evitarem a perda desnecessária de vidas numa possível reemergência do YFV.

Diferentemente do YFV, que, no Novo Mundo, saltou de um ciclo urbano, mantido pelo vetor doméstico $A e$ aegypti, para um ciclo enzoótico independente e não erradicável mantido por mosquitos silvestres, não há evidências de que os ZIKV, CHIKV e DENVs tenham feito mesmo no Brasil e nos demais países Americanos ${ }^{7,46,58}$. Mas é importante que a vigilância epidemiológica esteja qualificada e atenta, uma vez que há indícios de receptividade para esta mudança em nosso território ${ }^{46,58,70}$.

Com efeito, o risco de emergência epidêmica de outros arbovírus originários das Américas, como o vírus Mayaro (MAYV; Togaviridae, Alphavirus), ou africanos já circulantes no continente, como o WNV (Flaviviridae, Flavivirus), ou mesmo da invasão de outros vírus exóticos com potencial epidêmico, tal como o africano O'nyong-nyong (Togaviridae, Alphavirus), tem sido amplamente discutida ${ }^{1,46,71}$. O MAYV, que se assemelha ecologicamente ao YFV, pois também tem circulação enzoótica, silvestre e diurna, e os Haemagogus e PNHs como hospedeiros, tem causado surtos em áreas periurbanas e o Ae. aegypti se mostrou experimentalmente competente para transmiti-lo ${ }^{46,72}$. O WNV, que tem aves, especialmente as migratórias, como hospedeiras e várias espécies de mosquitos crepusculares e noturnos do gênero Culex como potenciais vetores naturais ${ }^{1,9}$, já causou epizootias de equinos e/ou casos humanos no Piauí e Ceará, mas também nos estados de São Paulo e Espírito Santo ${ }^{73-75}$. Os mosquitos Culex do complexo Pipiens, pernilongos comuns e noturnos cuja espécie $C x$. quinquefasciatus é muito frequente e abundante no Rio de Janeiro, são vetores competentes do WNV e tiveram importante participação em surtos no E.U.A., mesmo em cidades tão desenvolvidas como Nova York $^{1,8-10}$. Esse conjunto de exemplos ilustra o elevado risco dessas e/ou outras arboviroses emergirem no Rio de Janeiro.

\section{Conchusóes}

A aproximação dos ecossistema selvagens e urbanos, seja causada pelo desmatamento ou, em particular, promovida pelas tendências contemporâneas da "vida em comunhão com a natureza" ou da noção de uma vida em harmonia e proximidade com a floresta, precisam levar em conta que os desequilíbrios dessa relação supostamente harmoniosa, porém muito complexa, 
podem não ser percebidos ou ser notados tarde demais, dando-se a emergência de agravos à saúde humana de origem zoonótica, como foi o exemplo até recentemente impensado da reemergência da febre amarela no Rio de Janeiro. Com efeito, esse estado vem demonstrando elevadas receptividade e vulnerabilidade às arboviroses veiculadas por mosquitos nas últimas décadas. O fortalecimento da vigilância epidemiológica, do controle dos mosquitos urbanos, da educação em saúde, da formação de recursos humanos da área da entomologia médica e da pesquisa nos diferentes campos do conhecimento envolvidos na compreensão da transmissão das arboviroses é fundamental para o enfrentamento oportuno e eficiente desses fenômenos no estado.

\section{Agradecimentos E APOIO FINANCEIRO}

À Marcia G. de Castro pela ajuda na recuperação de alguns dados epidemiológicos, a Felipe V. Santos de Abreu pela leitura crítica do manuscrito e à Heloísa Diniz pela feitura das figuras. $\mathrm{O}$ trabalho e o autor receberam apoio financeiro do Conselho Nacional de Desenvolvimento Científico e Tecnológico (Proc. 312446/2018), e da Fundação Carlos Chagas Filho de Amparo à Pesquisa do Estado do Rio de Janeiro (Processos E-26/203.064/2016 e E-26/201.335/2016).

\section{Conflito DE INTERESSE}

O autor declara não haver conflitos de interesse.

\section{REFERÊNCIAS BIBLIOGRÁFICAS}

1. Weaver SC, Reisen WK: Present and future arboviral threats. Antiviral Res. 2010; 85(2): 328-345. doi: 10.1016/j. antiviral.2009.10.008.

2. Vasconcelos PFC, Calisher CH: Emergence of Human Arboviral Diseases in the Americas, 2000-2016. Vector Borne Zoonotic Dis. 2016;16(5):295301. doi: 10.1089/vbz.2016.1952.

3. CDC - Center for Diseases Control and Prevention: Arbovirus catalog. Available from: https://wwwn. cdc.gov/ arbocat/VirusBrowser.aspx (acessado agosto 2020).

4. Medeiros DBA, Vasconcelos PFC: Is the Brazilian diverse environment is a crib for the emergence and maintenance of exotic arboviruses? An Acad Bras Cienc. 2019; 91(Suppl. 3): e20190407. doi: 10.1590/0001-3765201920190407.

5. Figueiredo LTM: Arboviroses emergentes no Brasil. Rev Soc Bras Med Trop. 2007; 40(2):224-229. doi: 10.1590/s0037-86822007000200016.

6. Zouache K, Fontaine A, Vega-Rua A, Mousson L, Thiberge JM, Lourenco- 
de-Oliveira R, et al: Three-way interactions between mosquito population, viral strain and temperature underlying chikungunya virus transmission potential. Proc Biol Sci. 2014;281(1792):20141078. doi: 10.10 98/rspb.2014.107.

7. Lourenço-de-Oliveira R: Transmissão Vetorial. In: Valle D, Pimenta DM, Cunha RV (org,), Dengue: teorias e práticas. Rio de Janeiro, Editora Fiocruz. 2015, pp. 127-146.

8. Dauphin G, Zientara S, Zeller H, Murgue B: West Nile: Worldwide current situation in animals and humans. Comp. Immunol. Microbiol Infect Dis. 2004;27:343-355. doi: 10.1016/j.cimid.2004.03.009.

9. Kilpatrick AM, Daszak P, Jones MJ, Marra PP, Kramer LD: Host heterogeneity dominates West Nile virus transmission. Proc. Biol. Sci. 2006;273:2327-2333. doi: 10.1098/ rspb.2006.3575.

10. Ciota A, Kramer L: Vector-virus interactions and transmission dynamics of West Nile virus. Viruses. 2013; 5:3021-3047.

11. Rodhain F: Le parasite, le moustique, l'homme et les autres - essai sur l'éco-épidémiologie des maladies à vecteurs. Paris, Éditions Docis. 2015; p. 443.
12. Bruno-Lobo M, Bruno-Lobo G, Travassos J: Estudos sobre os arbovírus. II - Presença de anticorpos para certos vírus dos grupos $\mathrm{A}$ e $\mathrm{B}$ em soros de pessoas residentes no Rio de Janeiro. An Microbiol. 1961; 9:155-182.

13. Pinheiro FP, Schatzmayr H, Travassos da Rosa APA, Homma A, Bensabath G: Arbovirus antibodies in children of rural Guanabara, Brasil. Intervirology 1975;5:93-96. doi.org/ $10.1159 / 000149885$.

14. Castro MG, Travassos da Rosa APA, Lourenço-de-Oliveira R, Nogueira RMR, Schatzmayr HG, Deane LM: Piry virus antibodies in inhabitants of Rio de Janeiro. Mem Inst Oswaldo Cruz. 1993; 88(4):621-623.

15. Consoli RAGB, Lourenço-de-Oliveira R. Principais mosquitos de importância sanitária no Brasil. Rio de Janeiro, Editora FIOCRUZ. 1994; p 228.

16. Bonizzoni M, Gasperi G, Chen X, James AA: The invasive mosquito species Aedes albopictus: current knowledge and future perspectives. Trends Parasitol. 2013; 29(9):460-468. doi: 10.1016/j.pt.2013.07.003.

17. Carvalho R, Lourenço-de-Oliveira R, Braga IA: Updating the geographical distribution and frequency of Aedes albopictus in Brazil with remarks regarding its range in the Americas. Mem Inst Oswaldo Cruz. 2014; 109(6):78796. doi: 10.1590/0074-0276140304. 
18. Epelboin Y, Talaga S, Epelboin L, Dusfour I: Zika virus: An updated review of competent or naturally infected mosquitoes. PLoS Negl Trop Dis. 2017; 11(11): e0005933. doi:10.1371/journal.pntd.0005933.

19. Pereira-dos-Santos T, Roiz D, Lourençode-Oliveira R, Paupy C: A Systematic Review: Is Aedes albopictus an Efficient Bridge Vector for Zoonotic Arboviruses? Pathogens. 2020;9(4):266. doi: 10.33 90/pathogens9040266.

20. Powell JR, Tabachnick WJ: History of domestication and spread of Aedes aegypti — A review. Mem Inst Oswaldo Cruz. 2013; 108:11-17. doi:10.1590/ 0074-0276130395.

21. Powell JR, Gloria-Soria A, Kotsakiozi P: Recent history of Aedes aegypti: Vector genomics and epidemiology records. Bioscience. 2018; 68:854-860. doi:10.1093/biosci/biy119.

22. ECDC - European Centre for Disease Prevention and Control: Aedes aegypti - current known distribution: January 2019. Disponível em: https://www. ecdc.europa.eu/en/publications-data/ aedes-aegypti-current-known-distribution-january-2019 (acessado jul 2020).

23. Franco O: História da Febre Amarela no Brasil. Rio de Janeiro, Departamento Nacional de Endemias Rurais. 1969; vol. 1, p 208.
24. Possas C, Martins RM, Lourenço de Oliveira R, Homma A: Urgent call for action: avoiding spread and re-urbanisation of yellow fever in Brazil. Mem Inst Oswaldo Cruz. 2018; 113(1):12. doi: 10.1590/0074-02760170361.

25. Romano AP, Costa ZG, Ramos DG, Andrade MA, Jayme Vde S, Almeida MA, Vettorello KC, Mascheretti M, Flannery B: Yellow Fever outbreaks in unvaccinated populations, Brazil, 2008-2009. PLoS Negl Trop Dis. 2014;8(3):e2740. doi: 10.1371/journal. pntd.0002740.

26. Braga IA, San Martin JL: Histórico do Controle de Aedes aegypti. In: Valle D, Pimenta DM, Cunha RV (org,), Dengue: teorias e práticas. Rio de Janeiro, Editora Fiocruz. 2015, pp. 61-73.

27. Murugesan A, Manoharan M: Dengue virus. Emerg Reemerg Viral Pathog. 2020:281-359. doi: 10.1016/ B978-0-12-819400-3.00016-8.

28. Halstead SB, Cohen SN: Dengue Hemorrhagic Fever at 60 Years: Early Evolution of Concepts of Causation and Treatment. Microbiol Mol Biol Rev. 2015;79(3):281-91. doi: 10.1128/ MMBR.00009-15.

29. Osanai CH, Travassos da Rosa AP, Tang AT, do Amaral RS, Passos AD, Tauil PL: Dengue outbreak in Boa Vista, Roraima. Rev Inst Med Trop Sao Paulo. 1983;25:53-54. 
30. Nogueira RMR, Miagostovich MP, Schatzmayr HG, Santos FB, Araújo ESM, Filippis AMB, Zagne SM, Nicolai C, Baran M, Teixeira Filho G: Dengue in the State of Rio de Janeiro, Brazil 1986-1998. Mem Inst Oswaldo Cruz; 1999;94(3):297-304.

31. Nogueira RM, Miagostovich MP, Lampe E, Souza RW, Zagne SM, Schatzmayr HG: Dengue epidemic in the state of Rio de Janeiro, Brazil, 19901991: co-circulation of dengue 1 and dengue 2 serotypes. Epidemiol Infect. 1993;111(1):163-170. doi: 10.1017/ s0950268800056788.

32. Nogueira RM, Schatzmayr HG, Filippis AMB, dos Santos FB, da Cunha RV, Coelho JO, de Souza LJ, Guimarães FR, de Araújo ES, De Simone TS, Baran M, Teixeira Filho G, Miagostovich MP. Dengue virus type 3, Brazil, 2002. Emerg Infect dis. 2005;11:13761381. doi: 10.3201/eid1109.041043.

33. De Simone T S, Nogueira RMR, Araújo ESM, Guimarães FR, Santos FB, Schatzmayr HG, Souza RV, Teixeira Filho G, Miagostovich MP: Dengue virus surveillance: the cocirculation of DENV-1, DENV2 and DENV-3 in the State of Rio de Janeiro, Brazil. Trans R Soc Trop Med Hyg. 2004;98(9):553-562. doi: 10.1016/j.trstmh.2003.09.003.
34. Nogueira RMR, Eppinghaus ALF 2011. Dengue virus type 4 arrives in the State of Rio de Janeiro: a challenge for epidemiological surveillance and control. Mem Inst Oswaldo Cruz 106(6): 255-256. doi: 10.1590/s007402762011000300001.

35. Heringer $M$, Souza TMA, Lima MDRQ, Nunes PCG, Faria NRDC, de Bruycker-Nogueira F, Chouin-Carneiro T, Nogueira RMR, Dos Santos FB: Dengue type 4 in Rio de Janeiro, Brazil: case characterization following its introduction in an endemic region. BMC Infect Dis. 2017;17(1):410. doi: 10.1186/s12879-017-2488-4.

36. Castro MG, Nogueira RM, Filippis AM, Ferreira AA, Lima Mda R, Faria NR, Nogueira Fde B, Simôes JB, Nunes PC, Sampaio SA, Lourençode-Oliveira R, Santos FB: Dengue virus type 4 in Niterói, Rio de Janeiro: the role of molecular techniques in laboratory diagnosis and entomological surveillance. Mem Inst Oswaldo Cruz. 2012;107(7):940-945. doi: 10.1590/ s0074-02762012000700017.

37. Heringer M, Nogueira RM, de Filippis AM, Lima MR, Faria NR, Nunes PC, Nogueira FB, dos Santos FB: Impact of the emergence and re-emergence of different dengue viruses' serotypes in Rio de Janeiro, Brazil, 2010 to 2012. Trans R Soc Trop Med Hyg. 
2015;109(4):268-274. doi: 10.1093/ trstmh/trv006. Epub 2015 Jan 28.

38. Pereira-Dos-Santos T, Cruz OG, Silva $\mathrm{KAB}$, Castro MG, Ferreira-de-Brito A, Maspero RC, Alcântra R, Dos Santos FB, Honorio NA, Lourenço-deOliveira R: Dengue serotype circulation in natural populations of Aedes aegypti. Acta Trop. 2017; 176:140-143. doi: 10.1016/j.actatropica.2017.07.014.

39. Souza TM, Azeredo EL, BadolatoCorrêa J, Damasco PV, Santos C, Petitinga-Paiva F, Nunes PC, Barbosa LS, Cipitelli MC, Chouin-Carneiro T, Faria NR, Nogueira RM, de Bruycker-Nogueira F, Dos Santos FB: First Report of the East-Central South African Genotype of Chikungunya Virus in Rio de Janeiro, Brazil. PLoSCurr. 2017;9: ecurrents.outbreaks. 4200119978d62ccaa454599cd2735 727.doi:10.1371/currents.outbreaks. $4200119978 \mathrm{~d} 62 \mathrm{ccaa} 454599 \mathrm{~cd}$ 2735727.

40. Nunes MR, Faria NR, de Vasconcelos JM, Golding N, Kraemer MU, de Oliveira LF, Azevedo Rdo S, da Silva DE, da Silva EV, da Silva SP, Carvalho VL, Coelho GE, Cruz AC, Rodrigues SG, Vianez JL Jr, Nunes BT, Cardoso JF, Tesh RB, Hay SI, Pybus OG, Vasconcelos PF: Emergence and potential for spread of Chikungunya virus in
Brazil. BMC Med. 2015;13:102. doi: 10.1186/s12916-015-0348-x.

41. Souza TML, Vieira YR, Delatorre E, Barbosa-Lima G, Luiz RLF, Vizzoni A, Jain K, Miranda MM, Bhuva N, Gogarten JF, Ng J, Thakkar R, Calheiros AS, Monteiro APT, Bozza PT, Bozza FA, Tschoeke DA, Leomil L, Mendonça MCL, Rodrigues CDDS, Torres MC, Filippis AMB, Nogueira RMR, Thompson FL, Lemos C, Durovni B, Cerbino-Neto J, Morel CM, Lipkin WI, Mishra N: Emergence of the East-Central-South-African genotype of Chikungunya virus in Brazil and the city of Rio de Janeiro may have occurred years before surveillance detection. Sci Rep. 2019;9(1):2760. doi: 10.1038/s41598-019-39406-9.

42. Secretaria de Saúde do Estado do Rio de Janeiro: Chikungunya. Boletim epidemiológico arboviroses n. 006/2016. Disponível em: http://www.riocomsaude.rj.gov.br/Publico/MostrarArquivo. aspx?C=XFIn0UtahJ8\%3d (acesso ago 2020).

43. Secretaria de Saúde do Estado do Rio de Janeiro: Casos prováveis e confirmados de CHIKUNGUNYA por município/região de residência, segundo mês de início de sintomas, com frequências, óbitos e incidência por 100 mil habitantes, Estado RJ, ANO 2016. Disponível em:http://www.riocomsaude.rj.gov.br/ 
Publico/MostrarArquivo.aspx? $\mathrm{C}=\mathrm{rF}-$ vArc5RAVI\%3d (acesso ago 2020).

44. Vega-Rúa A, Zouache K, Girod R, Failloux $A B$, Lourenço-de-Oliveira R: High level of vector competence of Aedes aegypti and Aedes albopictus from ten American countries as a crucial factor in the spread of Chikungunya virus. J Virol. 2014; 88(11):6294-306. doi: 10.1128/JVI.00370-14. Epub 2014 Mar 26.

45. AragãoCF,PinheiroVCS, Nunes NetoJP, Silva EVPD, Pereira GJG, Nascimento BLSD, Castro KDS, Maia AM, Catete CP, Martins LC, Tadei WP, Silva SPD, Cruz ACR: Natural infection of Aedes aegypti by Chikungunya and Dengue type 2 Virus in a transition area of NorthNortheast Brazil. Viruses. 2019;11 (12):1126. doi: 10.3390/v11121126.

46. Pezzi L, Diallo M, Rosa-Freitas MG, Vega-Rua A, Ng LFP, Boyer S, Drexler JF, Vasilakis N, Lourenco-de-Oliveira R, Weaver SC, Kohl A, de Lamballerie X, Failloux AB GloPID-R chikungunya, o'nyong-nyong and Mayaro virus Working Group: GloPID-R report on chikungunya, o'nyong-nyong and Mayaro virus, part 5: Entomological aspects. Antiviral Res. 2020;174:104670. doi: 10.1016/j.antiviral.2019.104670. Epub 2019 Dec 5.
47. Brasil P, Calvet GA, Siqueira AM, Wakimoto M, de Sequeira PC, Nobre A, Quintana Mde S, Mendonça MC, Lupi O, de Souza RV, Romero C, Zogbi H, Bressan Cda S, Alves SS, Lourenço-deOliveira R, Nogueira RM, Carvalho MS, de Filippis AM, Jaenisch T: Outbreak in Rio de Janeiro, Brazil: clinical characterization, epidemiological and virological aspects. PLoS Negl Trop Dis. 2016;10(4):e0004636. doi: 10.1371/ journal.pntd.0004636.

48. 'Possas C, Brasil P, Marzochi MC, Tanuri A, Martins RM, Marques ET, Bonaldo MC, Ferreira AG, Lourençode-Oliveira R, Nogueira RMR, Sequeira PC, Marzochi KB, Homma A: Zika puzzle in Brazil: peculiar conditions of viral introduction and dissemination - A Review. Mem Inst Oswaldo Cruz. 2017;112(5):319-327. doi: 10.1590/0074-02760160510.

49. Secretaria de Saúde do Estado do Rio de Janeiro: Situação epidemiológica da dengue/Chikungunya/Zika e cenário para 2016 no estado RJ. Boletim epidemiológico n. 012/2015. Disponível em: http://www.riocomsaude.rj.gov. br/Publico/MostrarArquivo.aspx?C= FcNZ9arIgHg\%3d (acesso jul 2020).

50. Secretaria de Saúde do Estado do Rio de Janeiro: Casos prováveis e confirmados de ZIKA por município/região de residência, segundo semana de início 
de sintomas, com óbitos e incidência por 100 mil habitantes, Estado do RJ. Disponível em: http://www.riocomsaude.rj.gov.br/Publico/MostrarArquivo. aspx?C=Uowle3iRbvg\%3d (acesso jul 2020).

51. Bonaldo MC, Ribeiro IP, Lima NS, Dos Santos AA, Menezes LS, da Cruz SO, de Mello IS, Furtado ND, de Moura EE, Damasceno L, da Silva KA, de Castro MG, Gerber AL, de Almeida LG, Lourenço-de-Oliveira $\mathrm{R}$, Vasconcelos AT, Brasil P: Isolation of infective Zika virus from urine and saliva of patients in Brazil. PLoS Negl Trop Dis. 2016;10(6):e0004816. doi: 10.1371/journal.pntd.0004816.

52. Aliota MT, Bassit L, Bradrick SS, Cox B, Garcia-Blanco MA, Gavegnano C, Friedrich TC, Golos TG, Griffin DE, Haddow AD, Kallas EG, Kitron U, Lecuit M, Magnani DM, Marrs C, Mercer N, McSweegan E, Ng LFP, O’Connor DH, Osorio JE, Ribeiro GS, Ricciardi M, Rossi SL, Saade G, Schinazi RF, Schott-Lerner GO, Shan C, Shi PY, Watkins DI, Vasilakis N, Weaver SC Zika in the Americas, year 2: What have we learned? What gaps remain? A report from the Global Virus Network. Antiviral Res. 2017;144:223-246. doi: 10.1016/j.antiviral.2017.06.001.

53. Campos SS, Fernandes RS, Dos Santos AAC, de Miranda RM, Telleria EL,
Ferreira-de-Brito A, de Castro MG, Failloux AB, Bonaldo MC, Lourençode-Oliveira R: Zika virus can be venereally transmitted between Aedes aegypti mosquitóes. Parasit Vectors. 2017;10(1):605. doi: 10.1186/s13071017-2543-4.

54. Secretaria de Saúde do Estado do Rio de Janeiro: Cenário epidemiológico: dengue, Chikungunya e Zika no Estado RJ. Boletim epidemiológico $\mathrm{n}$. 001/2017. Disponível em: http://www. riocomsaude.rj.gov.br/Publico/Mostrar Arquivo.aspx?C=7eeHrPVyjGk\%3d (acesso jul 2020).

55. Possas C, Lourenço-de-Oliveira R, Tauil PL, Pinheiro FP, Pissinatti A, Cunha RVD, Freire M, Martins RM, Homma A. Yellow fever outbreak in Brazil: the puzzle of rapid viral spread and challenges for immunization. Mem Inst Oswaldo Cruz. 2018;113(10):e180278. doi: 10.1590/0074-02760180278.

56. Ministério da Saúde - Secretaria de Vigilância Epidemiológica. Saúde Brasil 2019: Uma análise da situação de saúde com enfoque nas doenças imunopreveníveis e na imunização. Disponível em: https://www.saude.gov.br/ images/pdf/2019/dezembro/05/SaudeBrasil-2019-imunizacao.pdf (acesso set 2020). 
57. Laemmert UW: Susceptibility of marmosets to different strains of Yellow Fever Virus. Am J Trop Med Hyg. 1944; s1-24:71-81.

58. Abreu FVS, Ferreira-de-Brito A, Azevedo AS, Linhares JHR, de Oliveira Santos V, Hime Miranda E, Neves MSAS, Yousfi L, Ribeiro IP, Santos AACD, Dos Santos E, Santos TPD, Teixeira DS, Gomes MQ, Fernandes CB, Silva AMVD, Lima MDRQ, Paupy C, Romano APM, Ano Bom APD, Oliveira-Pinto LM, Moutailler $S$, Motta MA, Castro MG, Bonaldo MC, Maria Barbosa de Lima S, Lourençode-Oliveira R: Survey on non-human primates and mosquitoes does not provide evidences of spillover/spillback between the urban and sylvatic cycles of yellow fever and Zika viruses following severe outbreaks in Southeast Brazil. Viruses. 2020 Mar 26;12(4):364. doi: 10.3390/v12040364.

59. Delatorre E, Abreu FVS de, Ribeiro IP, Gómez MM, dos Santos AAC, Ferreirade-Brito A, Neves MSAS, Bonelly I, de Miranda RM, Furtado ND, Raphael LMS, da Silva LFF, de Castro MG, Ramos DG, Romano APM, Kallás EG, Vicente ACP, Bello G, Lourençode-Oliveira R, Bonaldo MC: Distinct YFV lineages co-circulated in the Central-Western and Southeastern Brazilian Regions from 2015 to 2018.
Front Microbiol. 2019;10:1079. doi: 10.3389/fmicb.2019.01079.

60. Bonaldo MC, Gómez MM, Dos Santos AA, Abreu FVS, Ferreira-de-Brito A, Miranda RM, Castro MG, Lourençode-Oliveira R: Genome analysis of yellow fever virus of ongoing outbreak in Brazil reveals polymorphisms. Mem Inst Oswaldo Cruz. 2017;112(6):447451. doi: 10.1590/0074-02760170134.

61. Abreu FVS de, Ribeiro IP, Ferreira-deBrito A, Santos AAC dos, Miranda RM de, Bonelly IS, Neves MSAS, Bersot MI, Santos TPD, Gomes MQ, Silva JLD, Romano APM, Carvalho RG, Said RFDC, Ribeiro MS, Laperrière RDC, Fonseca EOL, Falqueto A, Paupy C, Failloux AB, Moutailler S, Castro MG, Gómez MM, Motta MA, Bonaldo MC, Lourenço-deOliveira R: Haemagogus leucocelaenus and Haemagogus janthinomys are the primary vectors in the major yellow fever outbreak in Brazil, 2016-2018. Emerg Microbes Infect. 2019;8(1):218-231. doi:10.1080/222 21751.2019.1568180.

62. Abreu FVS, Delatorre E, Dos Santos AAC, Ferreira-de-Brito A, de Castro MG, Ribeiro IP, Furtado ND, Vargas WP, Ribeiro MS, Meneguete P, Bonaldo MC, Bello G, Lourenço-de-Oliveira R: Combination ofsurveillancetools reveals that Yellow Fever virus can remain in 
the same Atlantic Forest area at least for three transmission seasons. Mem Inst Oswaldo Cruz. 2019;114:e190076. doi: 10.1590/0074-02760190076.

63. Secretaria de Saúde do Estado do Rio de Janeiro - SES-RJ: Informe Epidemiológico 020/2018. Monitoramento das emergências em saúde pública - Febre amarela. [Internet]. 2018. Disponível em: http://www.riocomsaude.rj.gov.br/ Publico/MostrarArquivo.aspx? $\mathrm{C}=\mathrm{L} 4 \mathrm{w}-$ qOoj4OVw\%3D (acessado Set 2020).

64. Soper FL. Yellow Fever: the present situation (October 1938) with special reference to South America. Trans R Soc Trop Med Hyg. 1938;32(3):297-322. doi: 10.1016/S0035-9203(38)90045-8.

65. Couto-Lima D, Andreazzi CS, Leite PJ, Bersot MIL, Alencar J, Lourençode-Oliveira R: Seasonal population dynamics of the primary yellow fever vector Haemagogus leucocelaenus (Dyar \& Shannon) (Diptera: Culicidae) is mainly influenced by temperature in the Atlantic Forest, southeast Brazil. Mem Inst Oswaldo Cruz. 2020; 115: e200218. doi: 10.1590/0074-02760 200218.

66. Causey OR, Laemmert HW, Kumm HW. Dispersion of forest mosquitoes in Brazil: further studies 1. Am J Trop Med Hyg. 1950;s1-30:301-312. doi: 10.4269/ajtmh.1950.s1-30.301.
67. Deane LM, Damasceno RG, Arouck R: Distribuição vertical de mosquitos em uma floresta dos arredores de Belém, Pará. Folia clínica biol. 1953;2:101110.

68. Forattini OP, Gomes AC: Atividade hematófaga de mosquitos Aedes scapularis (Rondani) e Haemagogus no sul do Brasil (Diptera: Culicidae). Rev Saúde Públ. 1988;22(2):84-93.

69. Ministério da Saúde-SVS: Monitoramento dos casos de arboviroses urbanas transmitidas pelo Aedes (dengue, chikungunya e Zika), Semanas Epidemiológicas 01 a 23, 2020. Situação Epidemiológica da Febre Amarela no monitoramento 2019/2020. Boletim Epidemiológico. 2020; 51(24). Disponível em: https://www.saude. gov.br/images/pdf/2020/June/16/ Boletim-epidemiologico-SVS-24-final. pdf (acessado Ago 2020).

70. Lourenço-de-Oliveira R, Failloux AB: High risk for chikungunya virus to initiate an enzootic sylvatic cycle in the tropical Americas. PLoS Negl Trop Dis. 2017;11(6):e0005698. doi: 10.1371/ journal.pntd.0005698.

71. Dodero-Rojas E, Ferreira LG, Leite VBP, Onuchic JN, Contessoto VG: Modeling Chikungunya control strategies and Mayaro potential outbreak in the city of Rio de Janeiro. PLoS One. 
2020 Jan 28;15(1):e0222900. doi: 10.1371/journal.pone.0222900. eCollection 2020.

72. Pezzi L, Rodriguez-Morales AJ, Reusken CB, Ribeiro GS, LaBeaud $\mathrm{AD}$, Lourenço-de-Oliveira R, Brasil P, Lecuit M, Failloux AB, Gallian P, Jaenisch T, Simon F, Siqueira AM, RosaFreitas MG, Vega Rua A, Weaver SC, Drexler JF, Vasilakis N, de Lamballerie $\mathrm{X}$; GloPID-R chikungunya, o'nyongnyong and Mayaro virus Working Group: GloPID-R report on chikungunya, o'nyong-nyong and Mayaro virus, part 3: Epidemiological distribution of Mayaro virus. Antiviral Res. 2019;172:104610. doi: 10.1016/j. antiviral.2019.104610.

73. Ministério da Saúde-SVS: Monitoramento da Febre do Nilo Ocidental no Brasil, 2014 a 2019. Disponível em: https:/www.saude.gov.br/images/ pdf/2019/julho/08/informe-febrenilo-ocidental-n1-8jul19b.pdf (acessado set 2020).

74. Governo do Estado do Ceará: Técnicos da Sesa e da Adagri investigam caso de Febre de Nilo Ocidental em equinos. Disponível em: https://www.ceara. gov.br/2019/09/10/tecnicos-da-sesa-e-da-adagri-investigam-caso-de-febrede-nilo-ocidental-em-equinos/ (acesso set 2020).

75. Governo do Estado de São Paulo Ceará: Ocorrência da febre do Nilo Ocidental em equino no Estado de São Paulo. Nota técnica CEDESA n.1/2019. Disponível em: https://www.defesa. agricultura.sp.gov.br/arquivos/sanidade-animal/nota-tecnica-febre-do-niloocidental.pdf (acesso set 2020). 